\section{Inspecting Surfaces With a Sharp \\ Stick: Scanning Probe Microscopy - Past, Present, and Future}

Paul West, Pacific Nanotechnology, Inc. pwest@pacificnanotech.com

With the growing emphasis on nanotechnology, scanning probe microscopy (SPM) is emerging from the surface science laboratories and becoming a mainstream inspection and metrology tool along side optical and SEM microscopes. Scanning probe instrumentation and applications evolved dramatically during the past quarter-century (Table I). By 1998 SPM-related papers were being published at the rate of nearly 5000 per year. Here we review the history of scanning probe microscopy, describe its current role as a critical enabler in nanotechnology, discuss why it has become a routine laboratory tool, and present a view of future directions for this advanced technology.

Table 1. Evolution of Scanning Probes and Applications

\begin{tabular}{|l|l|l|}
\hline & \multicolumn{1}{|c|}{ Instrument } & \multicolumn{1}{c|}{ Applications } \\
\hline $\begin{array}{l}1920- \\
1980\end{array}$ & Surface profilers & $\begin{array}{l}\text { Measurement of surface texture, } \\
\text { line profiles for step heights }\end{array}$ \\
\hline $\begin{array}{l}1980- \\
2000\end{array}$ & $\begin{array}{l}\text { Scanning probe } \\
\text { instruments }\end{array}$ & $\begin{array}{l}\text { Basic research, exploration, } \\
\text { engineering, physical science, life } \\
\text { science, process development }\end{array}$ \\
\hline $2001-?$ & Turnkey SPM & $\begin{array}{l}\text { Micro- and nano-device } \\
\text { manufacturing and process } \\
\text { control }\end{array}$ \\
\hline
\end{tabular}

\section{The Past}

Scanning probe microscopes (SPM) had their origins in optical-lever based mechanical profilers devised in 1929. This was enhanced by piezoelectric motion and detection in 1955, non-contact profilometry in 1972, culminating in the Nobel-prize-winning scanning tunneling microscope (STM) in 1982 that could actually produce images of atoms.

An optical-lever based mechanical profilometer was described by Gustav Schmalz (Germany) in 1929 [1]. His instrument, shown schematically in Figure 1, reflected a beam of light from a mirror on the sample probe mounted on a cantilever. The sample was on a moving stage and the reflected light traced a magnified image on photographic film moving in tandem with the sample. Profile magnifications up to $1000 \times$ could be achieved, but bending of the probe from collisions with large features on the surface presented a problem. In 1955 Helmut Becker, et al. (at Leitz in Germany) suggested oscillating the probe as it scanned the surface [2]. Figure 2 (from Becker's patent) shows the probe tip, 9 , with its motion

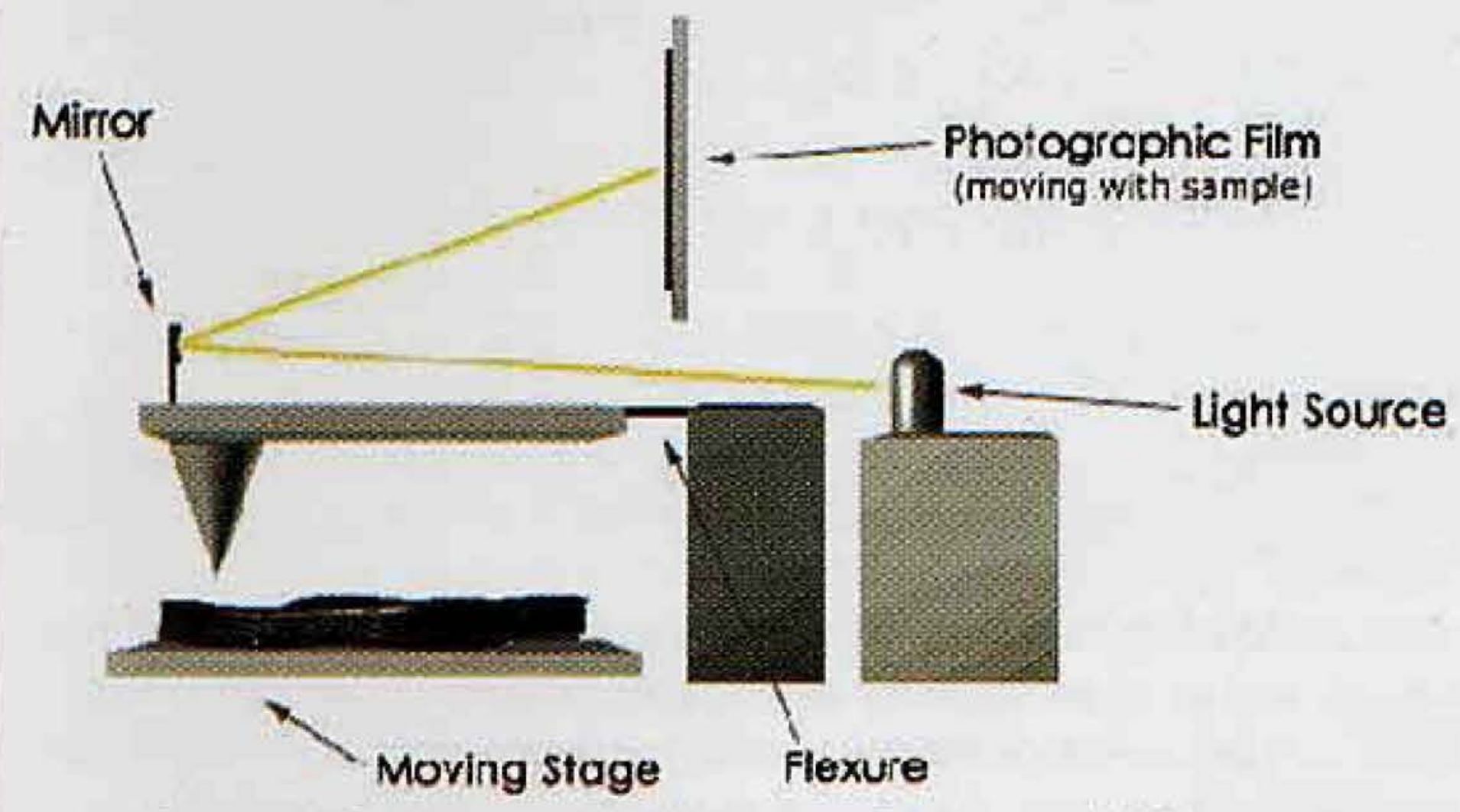

Figure 1. Schmalz optical-lever profilometer, 1929.

\section{Fig.1}

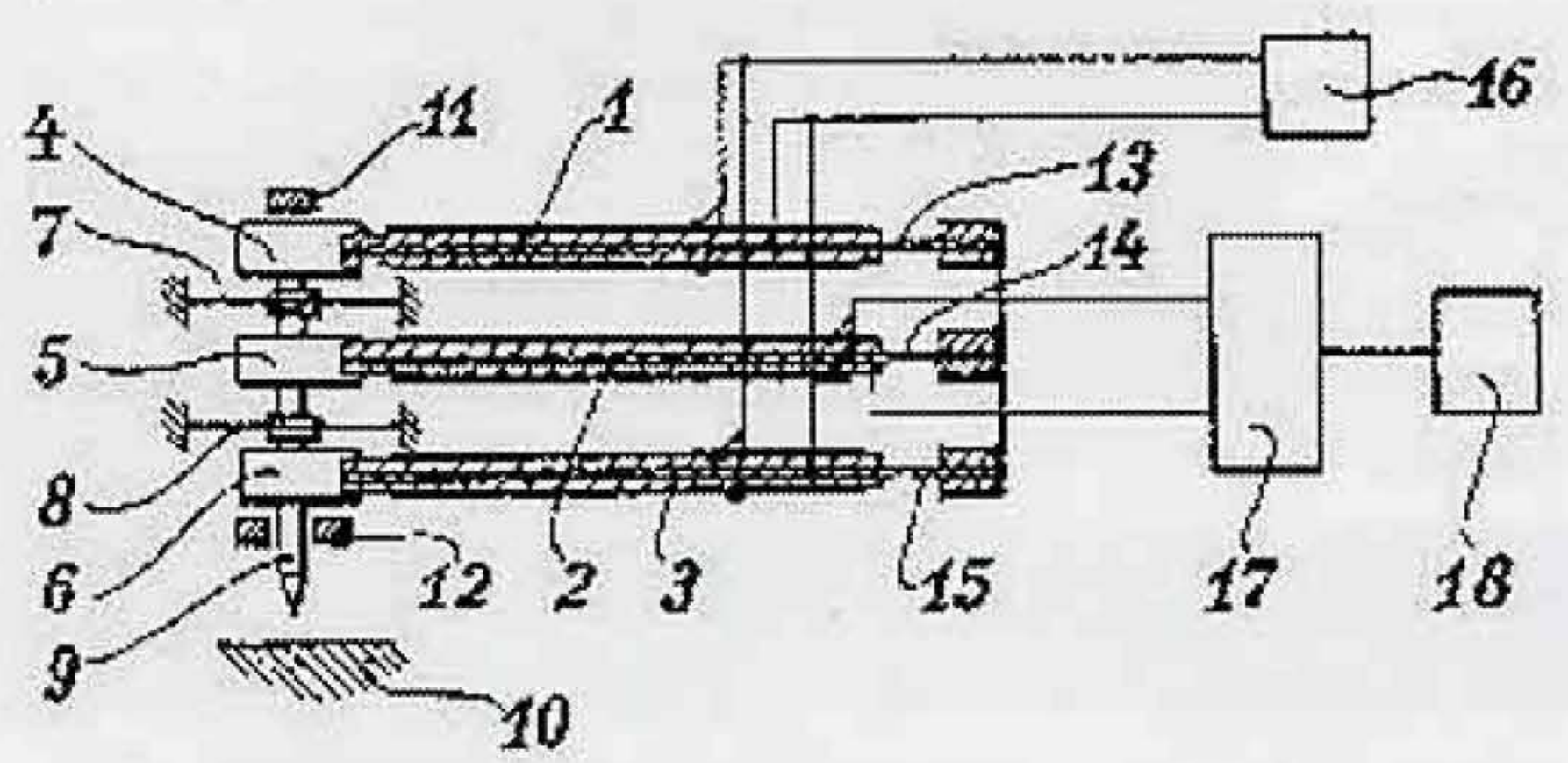

Figure 2. Figure from Becker's 1955 patent [2] for a vibrating probe controlled by piezoelectric elements 1 and 3 with signal output from the piezo element 2.

controlled by piezoelectric elements 1 and 3 . The middle piezo element, 2 , produced the probe height signal. The vibrating probe concept was also described by David Lee and Raymond Harrison in 1977 [3].

As acknowledged by the inventors of the STM in their Nobel lecture [4], the STM was presaged by an instruments devised in 1972 by Russell Young, John Ward and Fredric Scire at the U.S. National Bureau of Standards (Figure 3) [5]. This instrument, which they called the topographiner, was a non-contact profiler that used piezo control in the $\mathrm{x}$-, $\mathrm{y}$ - and $\mathrm{z}$-directions and constant current feedback from electronic field emission between the probe tip and the surface. The vertical resolution was $30 \mathrm{~A}$ and the horizontal resolution was about the same as an optical microscope.

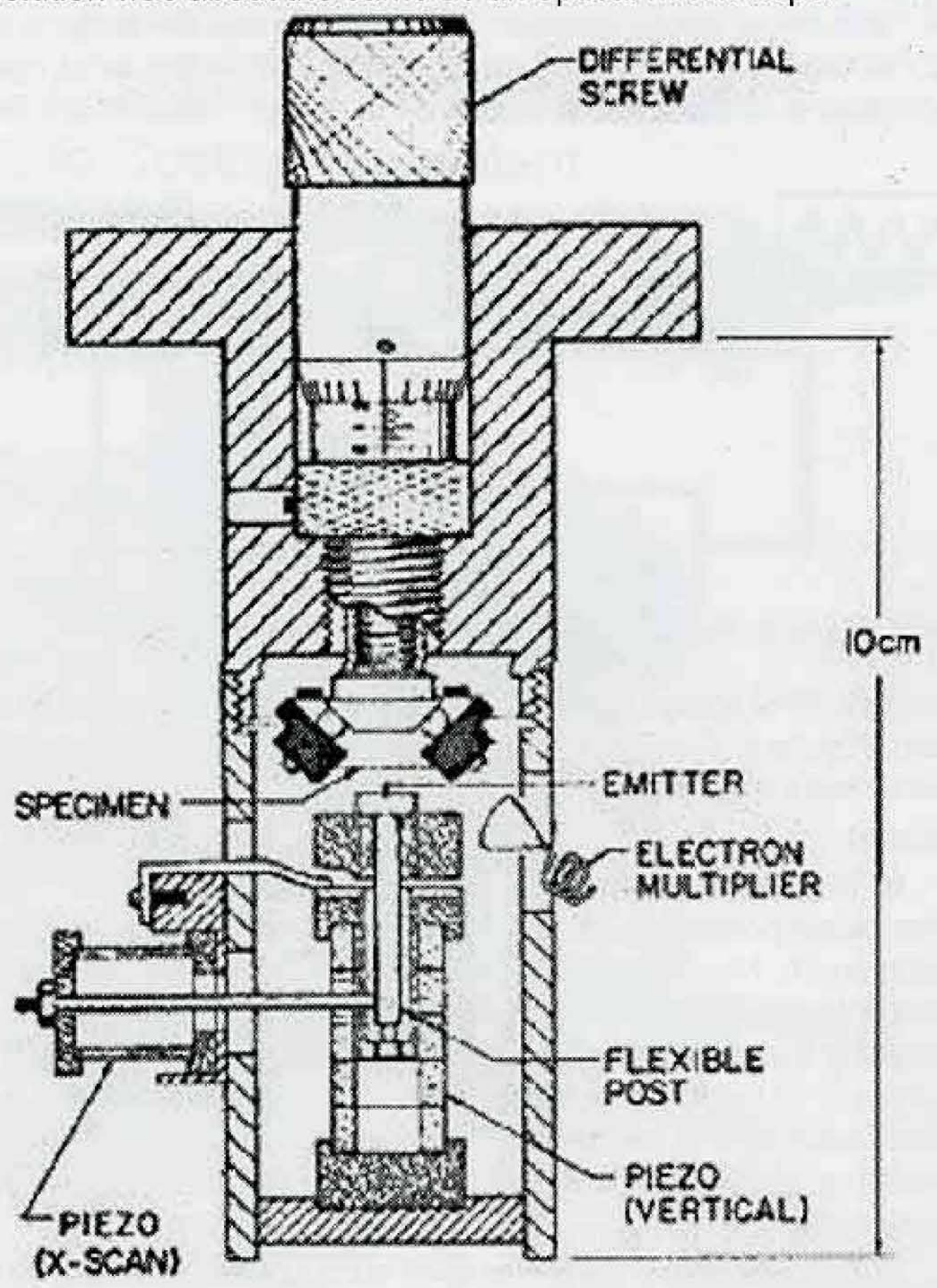

Figure 3. The topographiner (1972), a non-contact profiler with $x-y-z$ piezo control and constant current feedback (Figure from [57). 


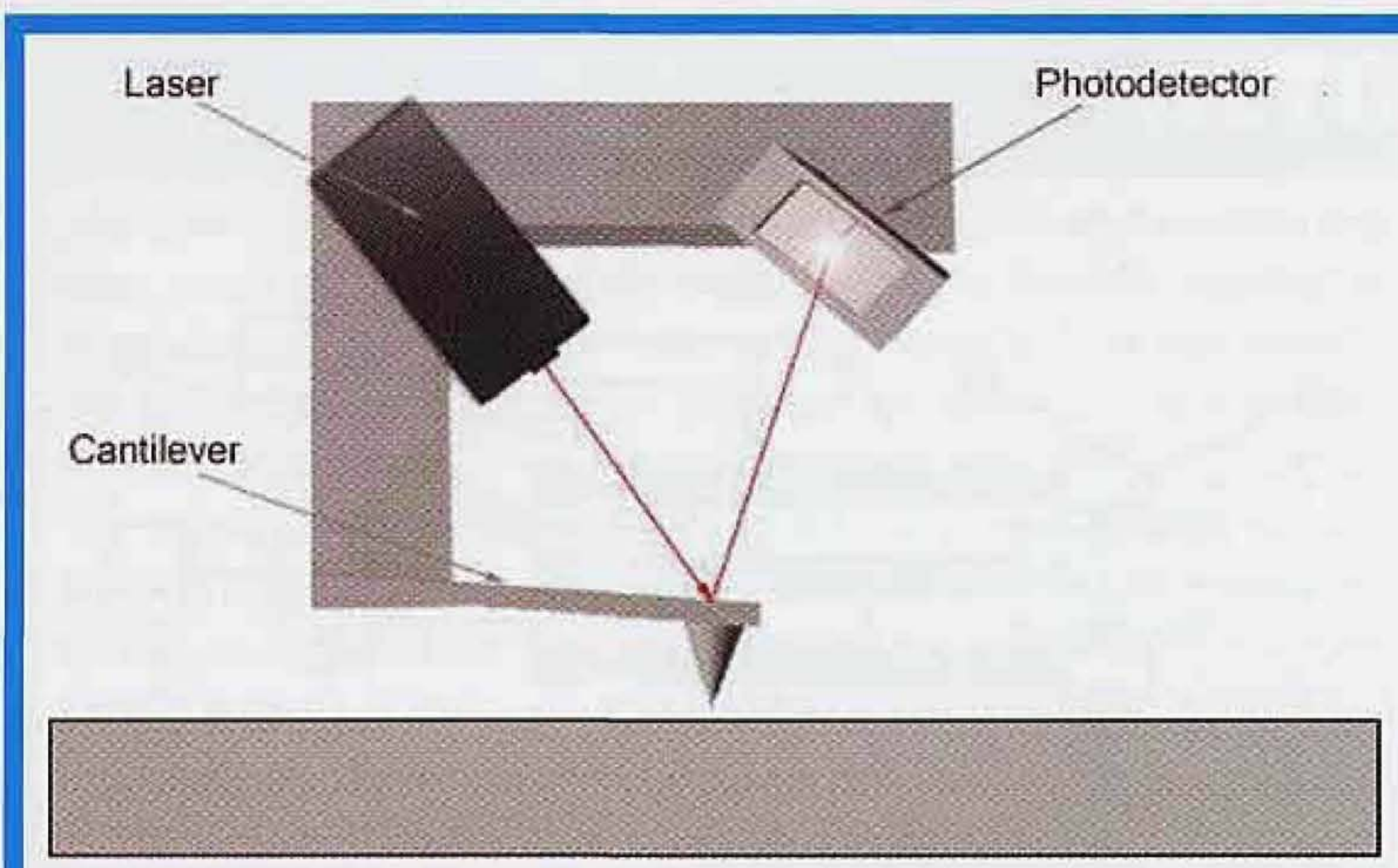

Figure 4. This figure illustrates the light lever sensor commonly used in atomic force microscopes [7].

In the fall of 1979 Gerd Binnig and Heinrich Rohrer at the IBM's Zurich Research Laboratory began experimenting with what became the scanning tunneling microscope that won them the Nobel Prize in 1986 [4]. Their instrument relied on the electron tunneling current flowing between a sharp conductive tip and the surface being scanned. They raster-scanned the probe to produce profiles that could be converted to a three-dimensional representation. In principle, the technique could provide atomic scale resolution, but required solving problems such as elimination of vibration and fabrication of an atomic-scale probe tip. They patented their device in 1982 [6].

The next milestone in SPM evolution was the atomic force microscope (AFM) invented in 1986 by Binnig, Calvin Quate (Stanford) and Christoph Gerber (IBM) [7]. This instrument relied on the mechanical forces between the probe tip and the surface and did not require a conducting tip or sample. While the most useful applications of the STM required an ultra-high vacuum ambient,

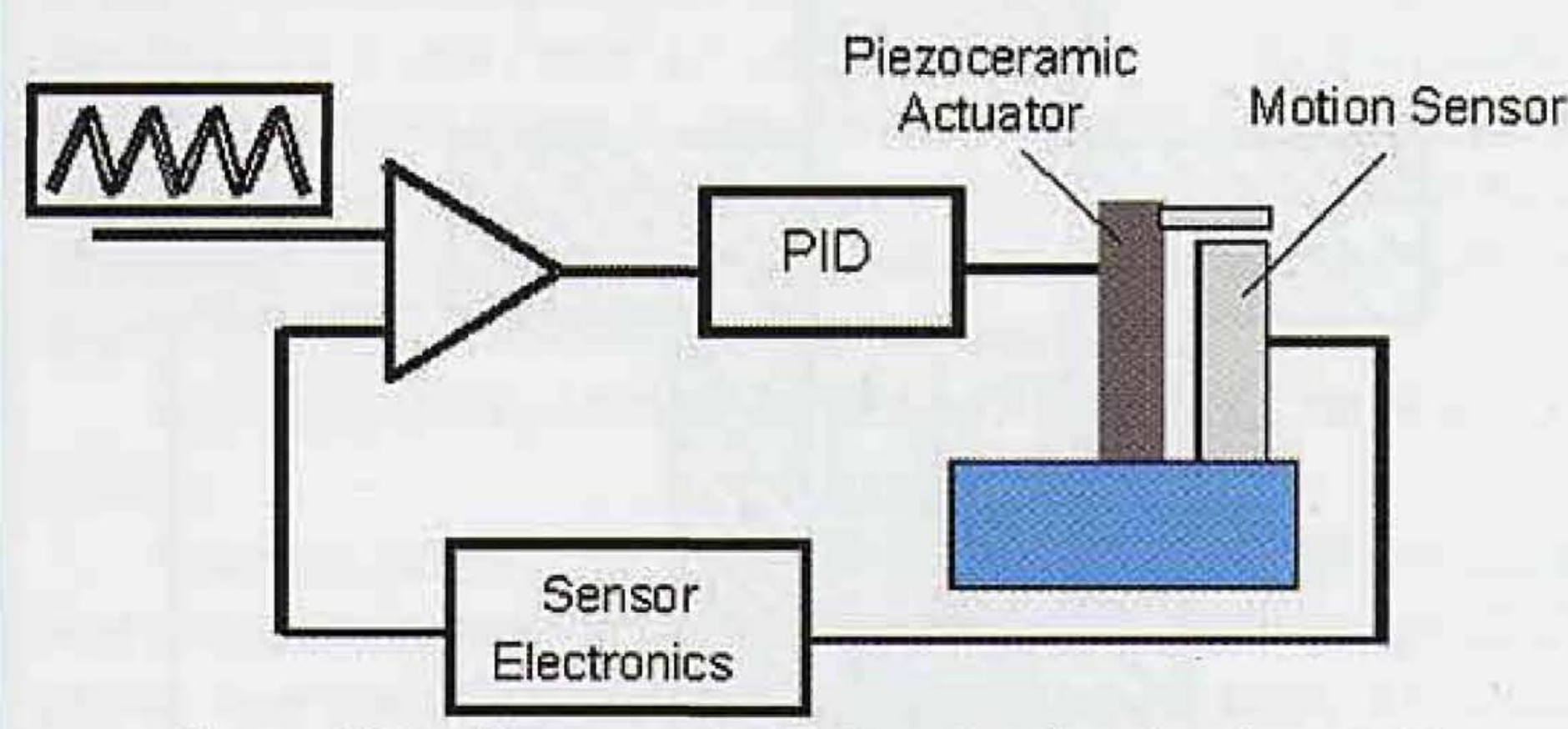

Figure 5. Position sensing and motion feedback control.

excellent AFM images could be obtained in air or even under a liquid. Figure 4 illustrates a light lever sensor commonly used in atomic force microscopes.

\section{Present}

SPMs became capable of accurate metrology in the 1990 s when probe position sensing and feedback control reduced image distortion [8]. Metrology step height standards of $18 \mathrm{~nm}$ and pitch standards of $0.5 \mu \mathrm{m}$ are now available with accuracies of $\pm 1 \%$. Computer control and position feedback (Figure 5 ) has given us intuitive SPM instruments that rapidly provide precise and accurate measurements and can be operated with little or no training. Their laboratory and industrial use is becoming as routine as optical microscopy.

In 1982, Bennig and Rohrer used cutout patterns from their recorder trace data to construct a Plexiglas model of the arrangement of atoms on a silicon surface [4]. Today, software can simultaneously generate 3D images of topography and physical properties of the
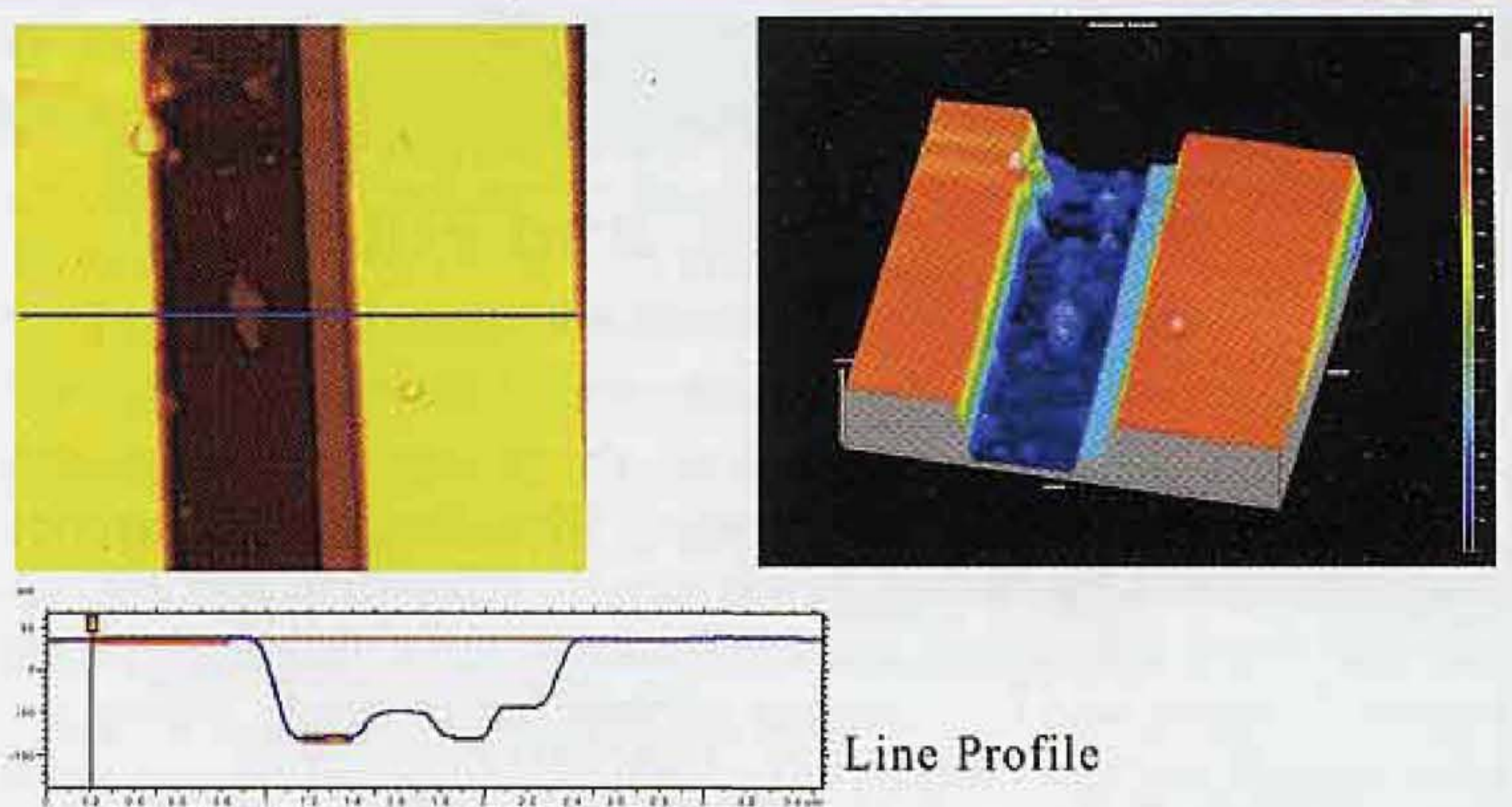

Figure 6. Modern software can convert scan data to a profile (lower left), 2D image (upper left) or a 3D image (right). (Source: Pacific Nanotechnology)

surface (Figure 6).

The means of motion control for these instruments has become more precise and modern SPMs use calibrated sensors to control the motion. Probe tips have evolved from electrochemicallyetched tungsten to chemically etched conical silicon to chemically deposited silicon nitride pyramids. Most recently, giant-molecule carbon nanotubes have been adapted as very high aspect ratio tips (Figure 7).
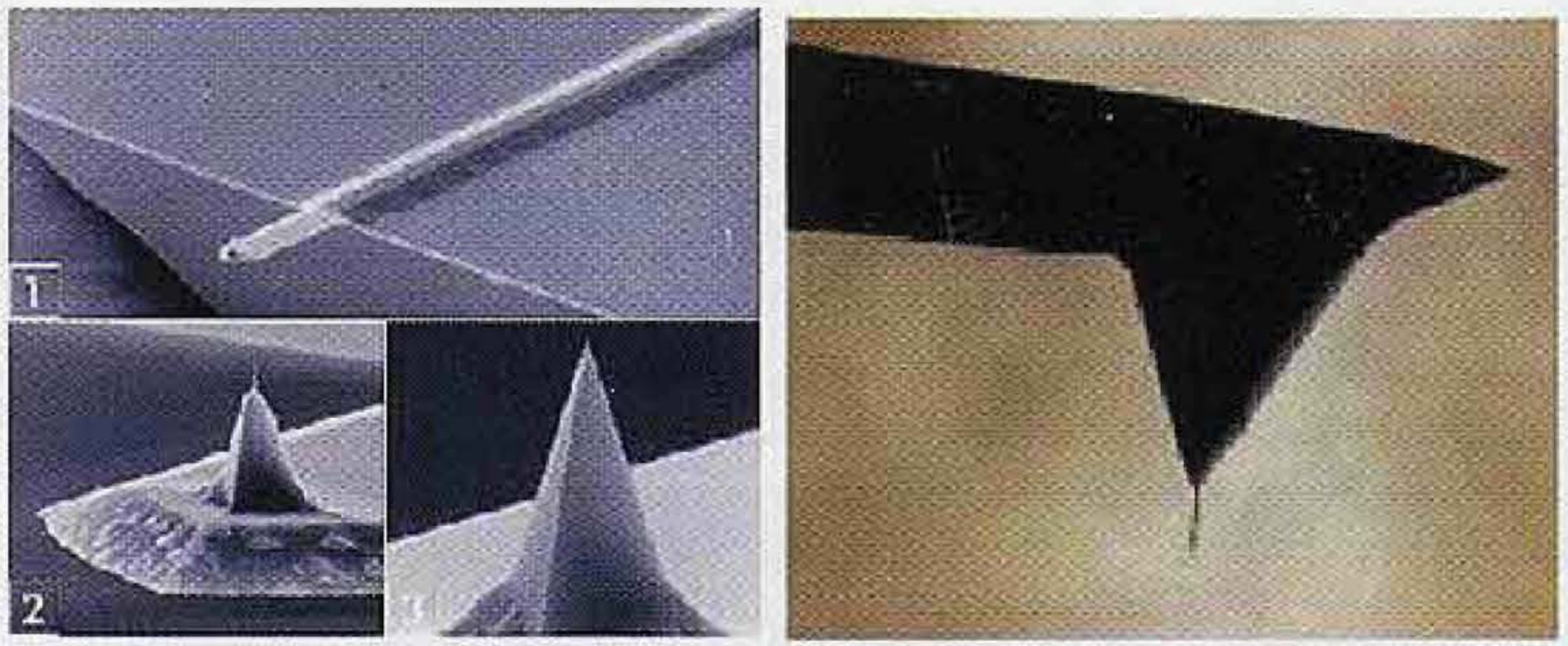

Figure 7. SPM probe tips. Left: (1) Silicon; (2) Silicon tip sharpened by focused ion beam machining; (3) Silicon tip sharpened by chemical etching (Source: NanoWorld). Right: carbon nanotube probe tip (Source: nPoint, Inc.).

Various imaging modes are available including continuous, vibrating, step-and-repeat, and lateral-force scanning (Figure 8). Lateral force scanning measures the lateral or twisting deflections of the probe from forces parallel to the surface. A recent application is the study of the of phase change of DNA molecules in response to tension and torsion [9]. In such applications, AFM cantilevers can measure angstrom-scale, millisecond events, and forces greater than $10 \mathrm{pN}$.

Applications have included basic research in surface science, and exploration in engineering, physical and life sciences, and nanoscale process development. More recent applications range from nanotechnology (including biotechnology) and nanoscience, to process development and process control.

SPMs have also been used for nanolithography, nanopatterning, and nano-construction. One example of nanolithography is the formation of an etch-resistant material by the action of an SPM tip. Nanopatterning can be accomplished directly by several methods. Direct action of a conducting AFM tip or STM tip can form an oxide pattern on metal by anodic oxidation or a metal pattern by chemical vapor deposition. Patterns with dimensions less than $10 \mathrm{~nm}$ can be achieved. A patterning technique called dip-pen nanolithography uses an AFM tip to deliver molecules to a surface via a solvent meniscus, just as in an ordinary dip ink pen. Molecular or biomolecular 'inks' can be used to write on a variety of substrates such as metals, semiconductors, and functional monolayers. Field evaporation in an AFM has been used to form $\mathrm{nm}$-sized gold dots on an $\mathrm{SiO}_{2} / \mathrm{Si}$ 


\section{ooming EVents}

GATAN 2003 Microscopy Training Schools

April 9-10, TEM Digital Microscopy

April 14-17, EELS Imaging \& Analysis

May 5-7, TEM Specimen Preparation

May 8-9, SEM Specimen Preparation

Pleasanton, $\mathrm{CA}$

mritter@gatan.com or www.gatan.com/training

$\checkmark \quad$ Histochemical Society Annual Meeting 2003

April 11-15, 2003, San Diego, CA

johc@u.washington.edu

$\checkmark \quad$ Experimental Biology

April 12-16, 2003, San Diego, CA

seb@sebiology.org

$\checkmark \quad$ Scanning 2003

May 3-5, 2003, San Diego, CA

www.scanning.org

$\checkmark \quad$ American Society for Microbiology

May 18-22, 2003, Washington, DC

www.asmusa.org

$\checkmark$ Microscopical Society of Canada

June 4-6, 2003, Vancouver, BC, Canada

ech@unixg.ubc.ca

$\checkmark \quad$ Lehigh Microscopy Schools

June 8 , Introduction to SEM \& EDS

June 9-13, SEM \& X-ray Microanalysis

June 16-20, Advanced SEM

June 16-20, Quantitative X-ray Microanalysis

June 16-19, Analytical TEM

June 16-19, Characterization of Nanostructures

June 16-19, Particle Characterization

June 17-19, TEM Specimen Preparation

June 17-20 Atomic Force Microscopy

sharon.coe@lehigh.edu

$\checkmark \quad$ Materials Research Society

April 21-25, 2003, San Francisco, CA

info@mrs.org

$\checkmark \quad$ Microscopy and Microanalysis 2003

August 3-7, 2003, San Antonio, TX

www.msa.microscopy.com

$\checkmark \quad$ Society for Neuroscience

November 8-13, 2003, New Orleans, LA web.sfn.org

$\checkmark \quad$ American Society for Cell Biology 2003

December 13-17, 2003, San Francisco, CA

www.ascb.org

$\checkmark \quad$ Materials Research Society

December 1-5, 2003, Boston, MA

info@mrs.org

$\checkmark \quad$ Microscopy and Microanalysis 2004

August 1-5, 2004, Savannah, GA

www.msa.microscopy.com

$\checkmark \quad$ EMC 2004 (former EUREM)

August 22-27, 2004, Antwerp, Belgium www.emc2004.be

$\checkmark \quad$ Microscopy and Microanalysis 2005 July 31 - August 4, 2005, Honolulu, HA www.msa.microscopy.com

Please check the "Calendar of Meetings and Courses" in the MSA journal "Microscopy and Microanalysis" for more details and a much larger listing of meetings and courses.
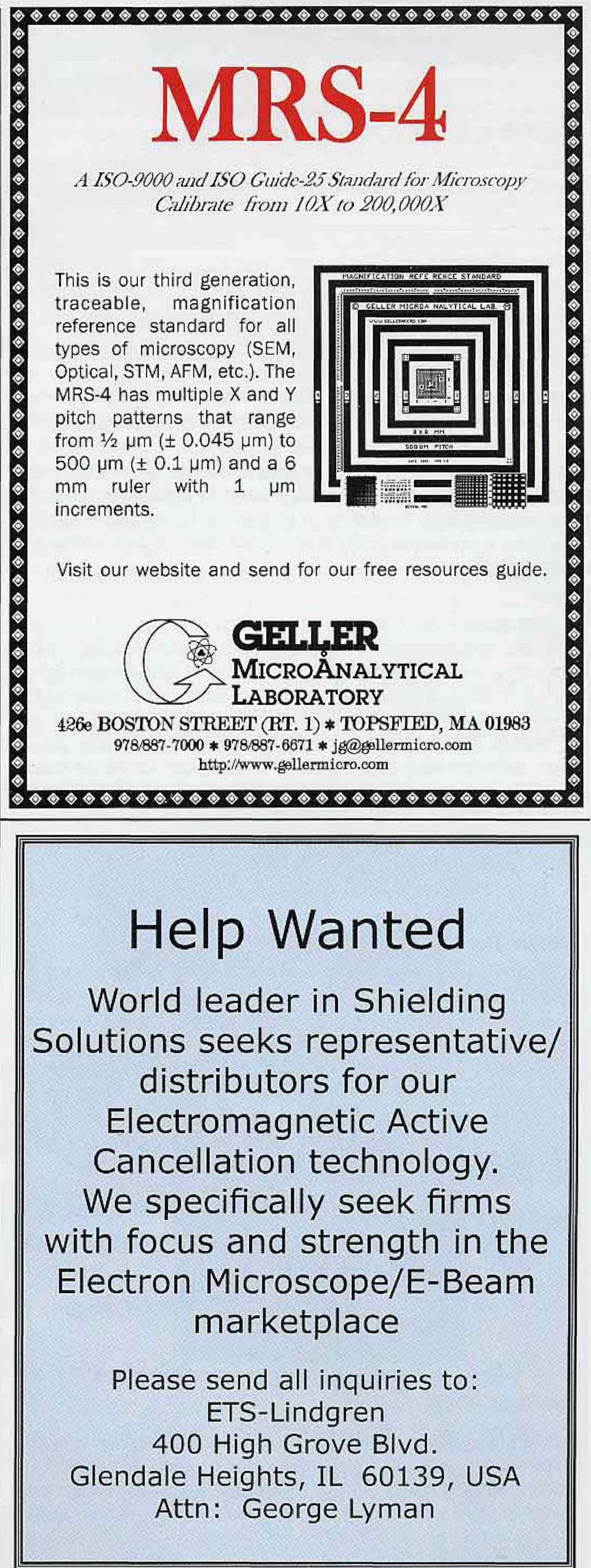


\section{Continuous Mode}

Contact Mode

Repulsive Region

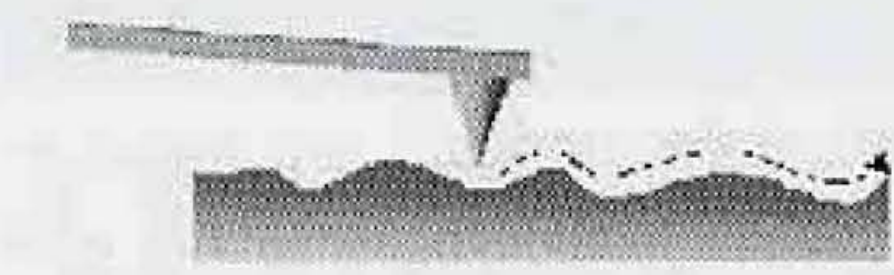

Vibrating Mode

Non-Contact

Intermittent Contact

"Tap"

\section{Material Sensing Modes \\ Lateral Force \\ Vibrating Phase}

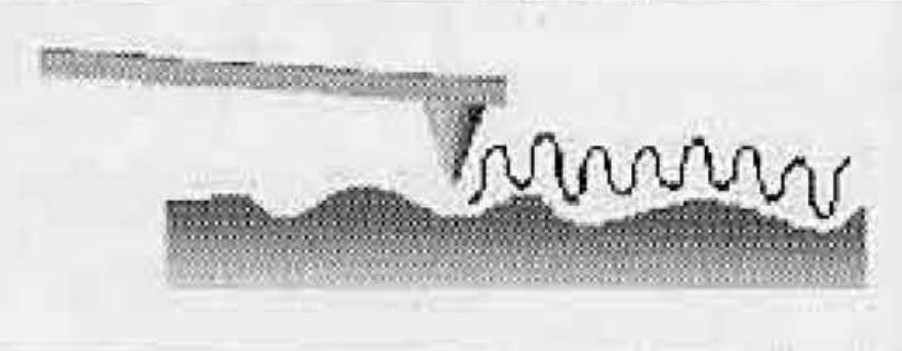

Figure 8. SPM scanning modes. Top: continuous, contact mode in repulsive region; Middle: vibrating mode, non-contact or intermittent contact ("tapping"). Bottom: material sensing modes that use lateral force or vibrating phase to measure surface properties such as friction.

substrate. Local heating by a near-field scanning optical microscope (NSOM) can change the phase of a GeSbTe optical recording film from amorphous to crystalline [10]. In nano-construction an STM tip is used to physically position adsorbed atoms to form a structure or pattern [11].

\section{Future}

Applications that were in the exploratory research phase in 1999 are now entering the marketplace. These include dip-pen lithography and "virtual reality" force-feedback nano-manipulation. The future will give us easy to use non-optical sensor systems that will enable new AFM applications. Force-feedback control will permit "feeling" the shape of surfaces, molecules and surface atoms. Probe materials will include glass or plastic, and we will be able to automatically sense when a probe is broken. Atomic-scale reference standards will be available. Fast data acquisition may be achieved by parallel scanning using arrays of multiple probes fabricated by MEMS techniques.

The ability to manipulate individual atoms will ultimately lead to practical computer memory with single-atom memory cells.

\section{Conclusion}

Scanning tunneling instruments have evolved into many offshoots, the first being the atomic force microscope, which have been used to observe nearly every physical property of a surface that it is possible to measure. Applications have included measurement of surface texture and step heights, and after 1980, scanning probe microscopes have been applied to basic research in surface

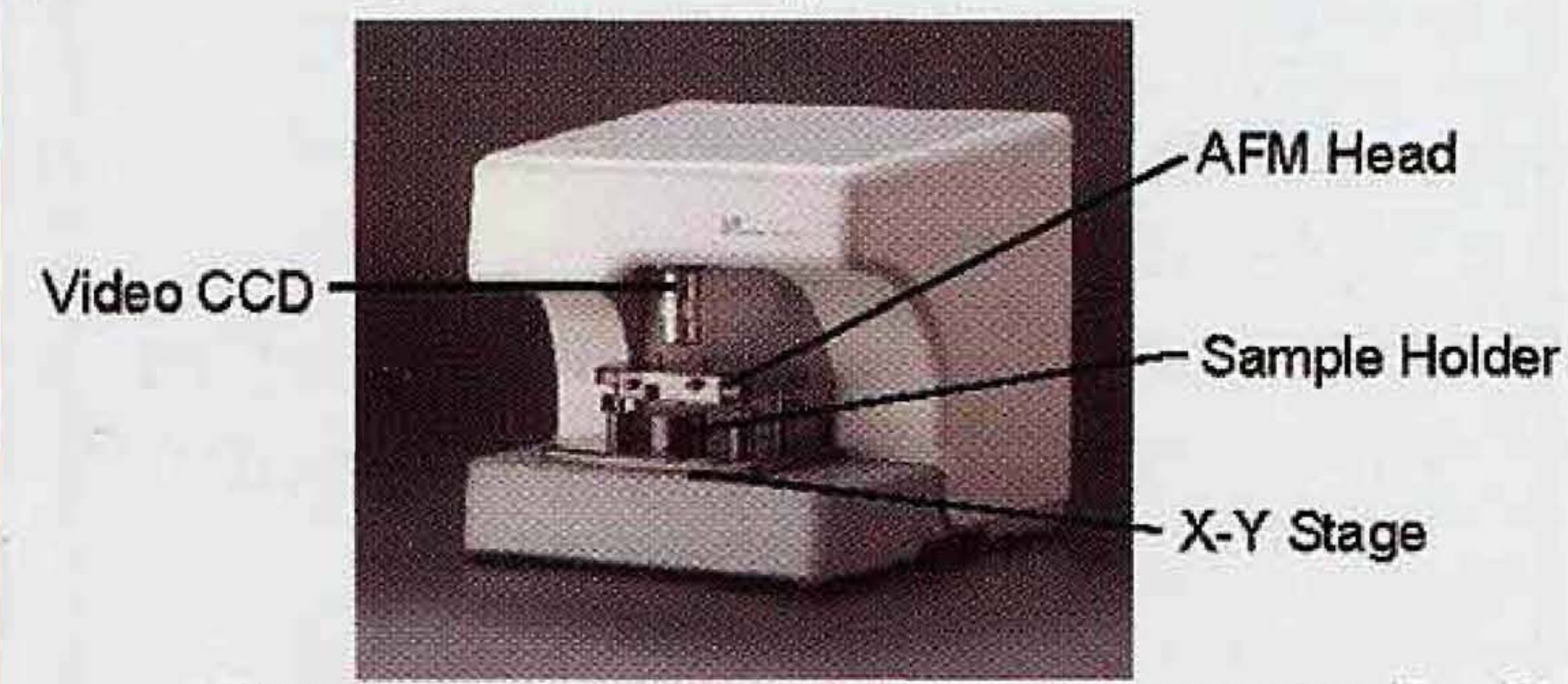

Figure 9. Tabletop atomic force microscope (Pacific Nanotechnology).

science and exploration in engineering, physical and life sciences, and nanoscale process development. Today, computer control and position feedback has given us intuitive SPM instruments that rapidly provide precise and accurate measurements and can be operated with little or no training (Figure 9). The laboratory and industrial use of SPMs is becoming as routine as optical microscopy.

\section{References}

1. G. Schmalz, Zeitschrift des Vereimes Deutcher Ingenieurte, Oct. 12, 1929, pp. 1461-1467.

2. H. Becker, et al., "Apparatus for Measuring Surface Irregularities," U.S. Patent 2,728,222 (27 Dec 1955).

3. D. Lee and R.G. Harrison, "Measuring and recording surface profile," U.K. Patent GB 2009409 (13 June 1979).

4. G. Binnig and $H$. Rohrer, "Scanning Tunneling Microscopy- From Birth to Adolescence," Rev. Mod. Phys. 59(3), Part 1, p. 615 (1987); [www.nobel.se/physics/laureates/1986/binnig-lecture.pdf].

5. R. Young, J. Ward, and F. Scire, "The Topografiner: An Instrument for Measuring Surface Microtopography," Rev. Sci. Instr. 43(7), pp. 999-1011 (1972). See also J. S. Villarurubia, R. D. Young, F. Scire, E. C. Teague, and J. W. Gadzuk, "The Topografiner: An Instrument for Measuring Surface Microtopography," in A Century of Excellence in Measurements, Standards, and Technology, NIST Special Publication 958, David R. Lide, Editor, pp. 214-218 (2000); [http://nvl.nist.gov/pub/nistpubs/sp958lide/214-218.pdf].

6. G. Binnig and H. Rohrer, "Scanning Tunneling Microscope," U.S. Patent 4,343,993 (10 Aug 1982).

7. G. Binnig, C.F. Quate and Ch. Gerber, "Atomic Force Microscope," Phys. Rev. Lett. 56(9), pp. 930-933 (1986).

8. J.E. Griffith, G.L. Miller, C.A. Green, D.A. Grigg and P.E. Russell, "A scanning tunneling microscope with capacitance-based position monitor," J. Vac. Sci. Technol. B 8(6), pp. 2023-2027 (Nov/Dec 1990).

9. T. Strick, J.-F. Allemand, V. Croquette, and D. Bensimon, "The Manipulation of Single Biomolecules," Physics Today 54(10) pp. 46-51 (Oct. 2001).

10. S. Hosaka, et al., "Fabrication of nanostructures using scanning probe microscopes," J. Vac. Sci. Technol. B 13(6), pp. 2813-2818 (Nov/Dec 1995).

11. T.A. Jung, et al., "Controlled Room-Temperature Positioning of Individual Molecules: Molecular Flexure and Motion," Science 271, pp. 181-184 (12 Jan 1996).

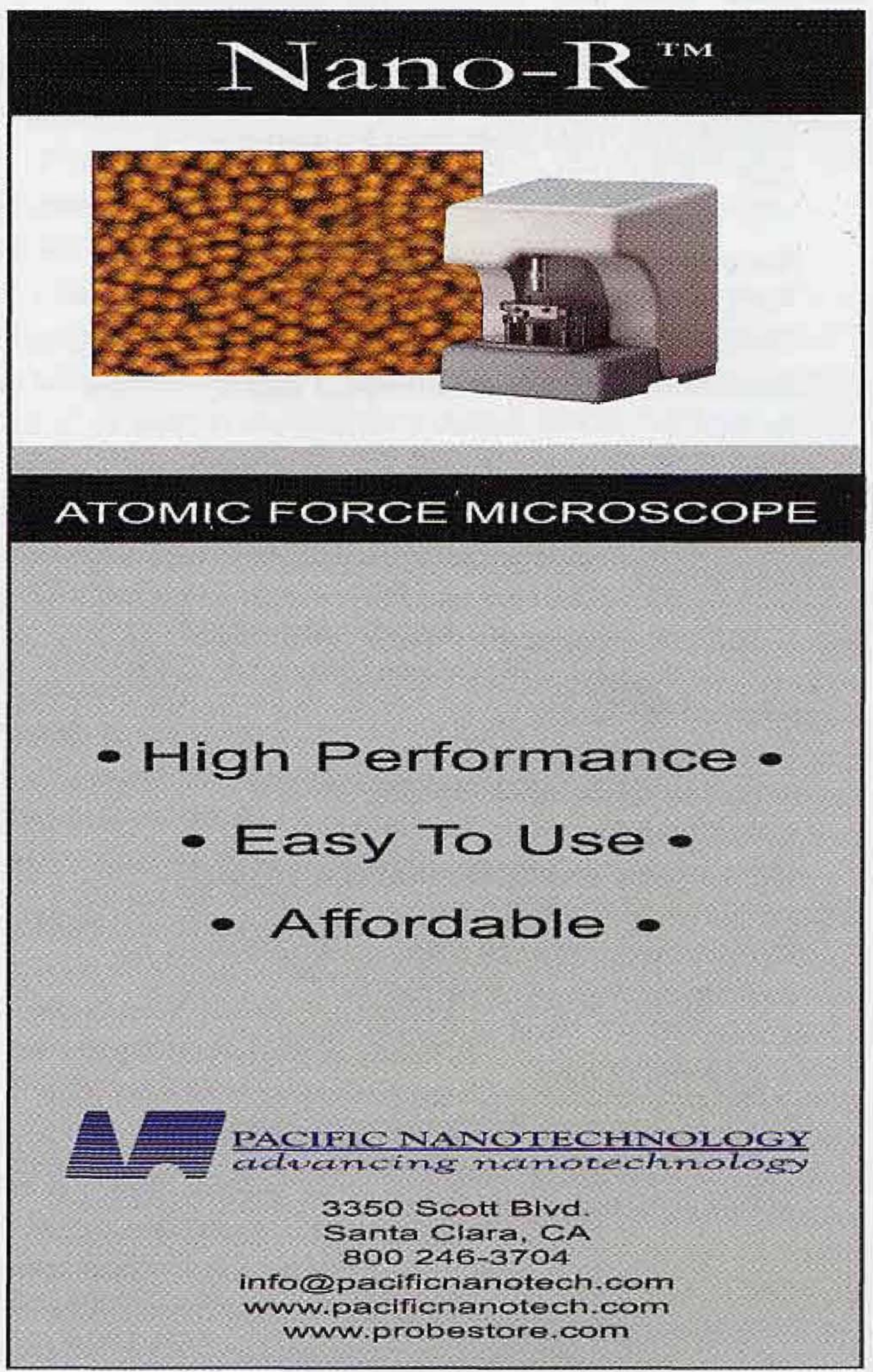




\section{Take Your Best Shot!}

Passion Flower

Pollen Grain -

$1500 x$ at $3 \mathrm{kV}$
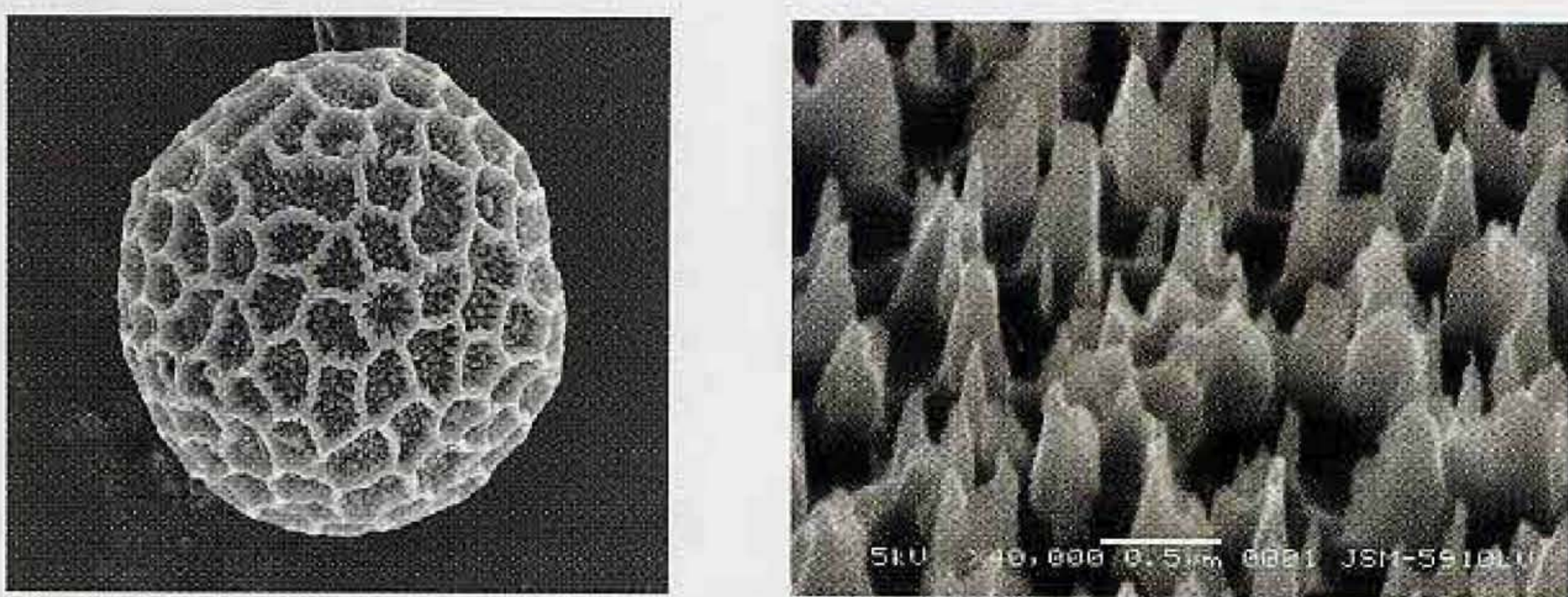

Teflon -

$40,000 x$ at $5 \mathrm{kV}$

Whether you're imaging pollen grains or CVD thin films, a JEOL SEM

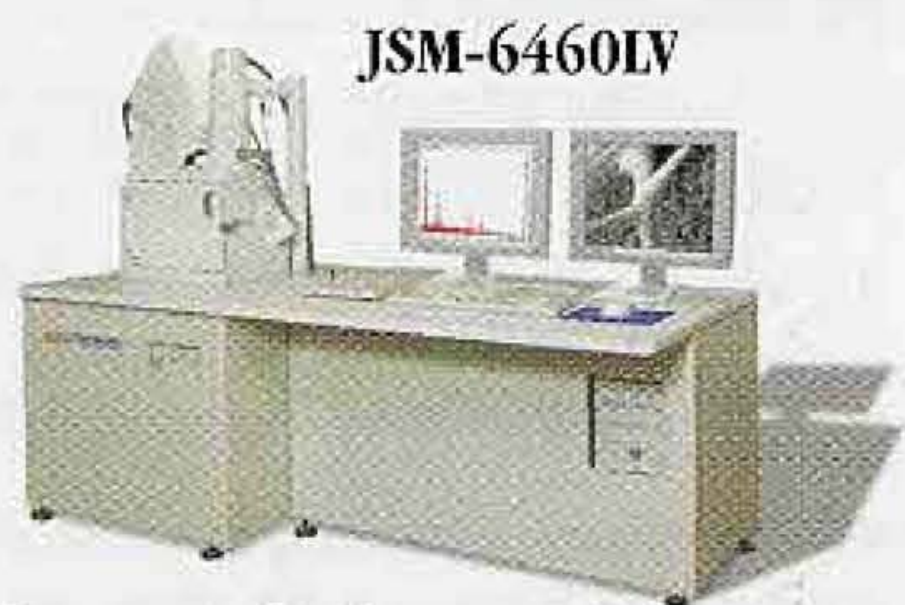
gives you your best shot at resolution, versatility, and ease of use.

That's why more microscopists specify JEOL scanning electron microscopes. Now the new

JSM-6460LV and JSM-6360LV improve on the legacy and performance of the JSM-5910LV industry workhorse. See for yourself the superior resolution necessary for the critical requirements of nanotechnology. The large chamber size for samples up to 8 inches wide and 3 inches tall. Simple, clear graphical user interface. A system that is easy to operate for multiple users and applications. And performance you can count on.

Get the picture? From forensics to semiconductors JEOL is the clear choice for your SEM applications.

For more information about the $6460 \mathrm{LV}$, give us a call or visit us at www.jeol.com/ 6460 /

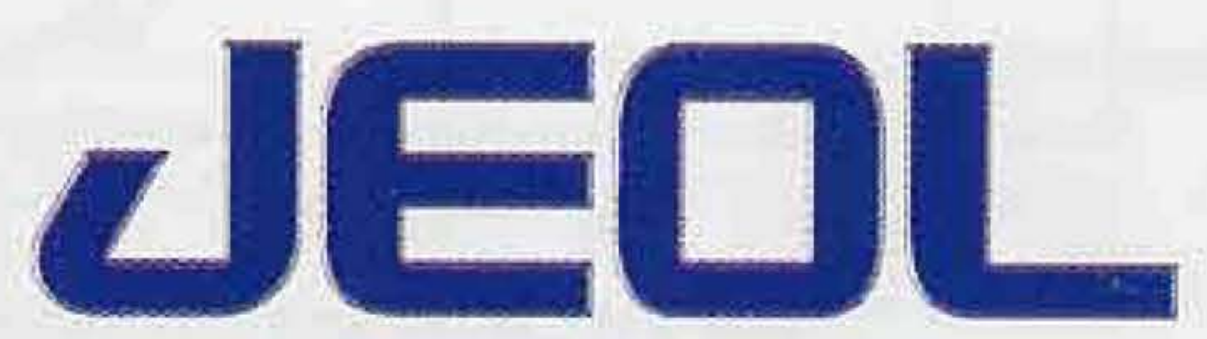

11 Dearborn Road, Peabody, MA 01960 (978)535-5900 eod@jeol.com 